Cad.Est.Ling., Campinas, (45):49-57, Jul./Dez. 2003

\title{
O ESTUDO DA MEMÓRIA SOB UMA ABORDAGEM NEUROLINGÜÍSTICA: AS INTER-RELAÇÕES ENTRE LINGUAGEM E MEMÓRIA
}

\author{
FERNANDA MIRANDA DA CRUZ \\ (UNICAMP)
}

\begin{abstract}
The aim of this paper is to show how Neurolinguistics can promote an interesting debate about the relationship between language and memory.
\end{abstract}

\section{OS ESTUDOS SOBRE A MEMÓRIA NO CAMPO DA LINGÜÍSTICA}

O objetivo deste artigo é mostrar como a Neurolingüística se constitui como um campo de estudo que autoriza uma pesquisa sistemática de relacionamento mútuo entre linguagem e memória. A primeira afirmação a considerar é que há uma relação entre esses dois processos. Assumido isso, não há como não considerar que os resultados obtidos em campos de estudos que pretendem compreender a memória não afetem diretamente a constituição de campos de estudos da linguagem e vice e versa.

Tradicionalmente o estudo da memória, bem como o de outros processos mentais, têm sido associados ao campo das neurociências. No entanto, embora possamos reconhecer os avanços científicos promovidos por este campo com respeito ao que se sabe sobre o cérebro e seu funcionamento, muitas ainda são as perguntas sobre a memória e seus modos de existência. Talvez não haja dúvidas (hoje em dia, pelo menos) sobre o fato de que a evocação de uma lembrança demande operações de ordem cerebral, mental. Mas seriam o cérebro ou as teorias em torno da estrutura e do funcionamento cerebral capazes de explicar todas as operações envolvidas na recordação? E ainda, seriam capazes de identificar quais seriam "todas" essas operações? Certamente não esgotaremos aqui todas essas questões, mas adianto que conhecer intimamente os mecanismos neurofisiológicos do cérebro nos deixa longe de compreender o que está em jogo nas relações entre linguagem e memória. Tratar da memória em sua relação com a linguagem introduz uma questão interdisciplinar, marcada por dois campos já instituídos e independentes: o campo das Neurociências, ao qual a memória é tradicionalmente reputada como objeto de estudo, e o campo da Lingüística, que trataria então das questões de linguagem.

Quando propomos uma reflexão sobre a memória a partir da linguagem podemos de antemão entrever que um fenômeno multifacetado como aquele pode interessar à Lingüística de várias formas ${ }^{1}$. No fundamento das teorias de dois importantes autores na história das idéias lingüísticas, Saussure e Chomsky, o conceito de língua (para o primeiro) ou de competência lingüística (para o segundo) pressupõem uma noção de memória. No Cours de Linguistique Général, a língua é concebida como um "tesouro depositado" na mente dos falantes (Saussure, 1981:21), pelo uso. Para a teoria chomskyana, a concepção inata da capacidade para adquirir linguagem pressupõe um conjunto de princípios e parâmetros antes armazenados na mente dos falantes. Língua e conteúdos mnêmicos praticamente se fundem na noção de "língua-memória". 
Benveniste, em Problèmes de Linguistique Géneral, ao discutir que seriam categorias do pensamento ou categorias da língua, admite que pensar e falar são duas atividades distintas. Ainda que distinta, a linguagem é entendida como um conteúdo de pensamento e esse conteúdo só recebe forma quando é enunciado. Daí que para Benveniste o papel da língua é "enformar", uma vez que "dá a sua forma ao conteúdo do pensamento."2 Isto nos leva a aceitar, sem questionamentos, uma relação entre língua e pensamento. No entanto, admitir a existência dessa relação e tomar como base que tanto linguagem como pensamento são solidários ${ }^{3}$, ainda nos deixam muito longe de compreender o que realmente se dá entre eles para além de uma vaga idéia de constitutividade e representabilidade. Com relação aos termos memória e linguagem, podemos dizer o mesmo. Lembrar e falar são dois atos distintos, ainda que os conteúdos da memória só pareçam ganhar forma quando enunciados. Memória e linguagem são também dois processos distintos, porém, não se pode negar que haja entre eles uma relação. Mas, admitir a existência desta relação também não nos explica sobre a qualidade e os termos dessa relação.

No campo dos estudos da linguagem, parte-se, de maneira explícita ou implícita, de uma relação existente entre memória e linguagem para dar conta de determinados fenômenos e práticas lingüísticas, em níveis diversos (formal, textual, discursivo, pragmático). Aqui podemos citar, de forma breve, as pesquisas desenvolvidas no campo das teorias cognitivistas que lançam mão da idéia de memória para explicar a construção e o armazenamento da noção de modelos (mentais) de situação pelos falantes de uma língua ( $c f$. Van Dijk,1988); no campo da Psicolingüística ou da Gramática Gerativa, a utilização do conceito de "memória de trabalho" (Baddeley, 1986) para explicar o processamento lingüístico (ou parte dele, como o sintático, o morfológico, o semântico) ou ainda abordagens nas quais a noção de memória como armazenamento é utilizada para dar a termos como "discurso", "situação de comunicação", uma idéia de conteúdo armazenado e compartilhado pelos falantes, que se constitui de saberes de conhecimento e de crenças sobre o mundo, do reconhecimento de "dispositivos e contratos de comunicação", das maneiras de dizer ou estilos de falar, do reconhecimento de certos enunciados conservados, renovados, retomados ou esquecidos, como apontados nos trabalhos de Courtine (1981), Maingueneau, (1987), Maingueneau \& Charaudeau (2000). Língua e memória se entrecruzam também a partir do reconhecimento de instituições de

${ }^{1}$ Seja no campo lingüístico, seja fora dele, podemos pensar sobre a forma como esses dois processos, ou essas duas formas de cognição, estão associados. Um exemplo disto são os estudos sociológicos, como os de Halbwachs $(1925,1951)$, para quem a compreensão dos chamados quadros sociais da memória centra-se basicamente no importante papel ocupado pela linguagem. Primeiro porque é ela que constitui a base desses quadros interativos e segundo porque as convenções verbais seriam entendidas por este autor como o constituinte "mais elementar e estável" da memória coletiva. Para um entendimento das relações entre linguagem e memória é preciso estabelecer um diálogo com áreas do conhecimento que tomam a questão da memória como um problema também seu, ou que se dedicaram a entender o que estaria na base da compreensão da memória. Em muitos estudos que se preocupam com a questão da memória, a linguagem aparece como um componente, seja direto ou indireto, para sua compreensão, como se observa em trabalhos de autores da sociologia (Halbwachs, 1925, 1951) da antropologia (Weinrich, 2001, Candau, 1996), da psicologia social (Bosi, 1984), da história (Burke 2001, Le Goff, 1924). Mas também nas "narrativas de memória", (como "Cem anos de solidão", do escritor Gabriel Garcia Márquez, e "Em busca o tempo perdido", de Marcel Proust), ou na literatura teórica, cujo tema é a função subjetiva e social da memória através das narrativas, portanto, da linguagem, como as obras de Umberto Eco, "Seis passeios pelo bosque da ficção", Wolfgang Iser, "O fictício e o imaginário", e Walter Benjamin, "O narrador"”. Esses são apenas alguns exemplos de estudos que evidenciam, cada um a sua maneira, a imbricada relação entre linguagem e memória, passível de ser explorado por vários campos do saber.

${ }^{2}$ Benveniste, E. (1976) Problemas de Lingüística Geral, p.69.

${ }^{3}$ Nas palavras de Benveniste: "Apresentar esses dois termos, pensamento e língua, como solidários e mutuamente necessários não nos indica a forma pela qual são solidários, nem a razão porque os julgaríamos indispensáveis um ao outro.” (op.cit.p.69) 
linguagem como lugares de memória ( $c f$. Pierre Nora), seja a partir da existência de determinadas formas lingüísticas - como formas mnêmicas de preservação, de recuperação, de conservação e de comemoração, como os gêneros discursivos; seja nas instituições de linguagem (os regimes e as práticas de discurso, como as escolas científicas, os tribunais); seja nos espaços discursivos da comemoração (os rituais verbais de comemoração a datas nacionais, celebrações de eventos e de grandes homens); nas instituições-memória da própria língua (como os dicionários, as enciclopédias de línguas, que guardam os "tesouros da língua"), etc.

Ainda que se reconheça que a Lingüística, de alguma forma, tenha se atentado à questão da memória, talvez o problema levantado por Weinrich (1990) acerca da "indiferença negligente"4 dos lingüistas frente ao tema ainda esteja vigente no cenário atual. A memória tem sido vista, grosso modo, de forma reduzida, como capacidade de armazenamento e processamento (sintático, lingüístico, textual) dos conteúdos lingüísticos.

\section{AS BASES CONCEITUAIS QUE FUNDAMENTAM A INVESTIGAÇÃO DA MEMÓRIA EM CONTEXTOS PATOLÓGICOS}

Vinculadas a uma certa concepção de ciência que busca a objetividade e explicações de cunho científico aferidas empiricamente, as neurociências veiculam um certo saber, portanto, um certo discurso sobre o que vem a ser a memória e sua relação com outros processos, dentre eles a linguagem. A memória de que trata as neurociências parece ser aquela a que Israel Rosenfield (1939), em " $A$ invenção da memória", definiu como mito, pela expectativa em relação à propriedade de uma memória que permita recuperar tudo o que foi armazenado e cujas imagens estariam impressas em nosso cérebro, servindo de base para nosso pensamento e para nossas ações.

As teorias sobre memória (seu funcionamento normal ou patológico e sua relação com outros processos cognitivos) orientam procedimentos clínicos terapêuticos em casos de patologias e alterações, como atestam, por exemplo, testes neuropsicológicos que procuram avaliar as alterações de linguagem e de memória em pacientes cérebro-lesados. Como exemplos deste tipo de procedimento podemos citar algumas baterias de testes, como o Mini-mental State (1974), o Exame Neuropsicológico por Anne-Lise Christensen (1987), o Protocolo de Confabulação, de Dalla Barba (1993), o WAIS (Wechsler Adult Intelligence), a Bateria de Boston. Esses protocolos de investigação, comprometidos com uma metodologia quantitativa e com uma visão mentalista dos processos cognitivos, são aplicados para diagnosticar tanto alterações de memória (síndromes frontais, demências e senilidades), quanto afasias, são compostos de muitas tarefas verbais (na verdade, tarefas metalingüísticas). A partir destes testes podemos tecer um eixo de discussões de ordem teórica, no que se refere às concepções de memória e de linguagem ali subjacentes, e de ordem metodológica, referente à forma como elas são investigadas.

Qual tem sido o papel da linguagem frente à memória em abordagens desse tipo? Ao observarmos como e que tipo de memória se analisa nestes testes, nos deparamos com uma tipologia que procura diferenciar o que seria, por exemplo, memória de fixação, memória de evocação, memória verbal e linguagem. Vejamos algumas implicações deste tipo de classificação e, portanto, conceituação da memória, a partir da análise de dados extraídos da aplicação do "Mini Exame do Estado Mental" $(\mathrm{MEEM})^{5}$, amplamente utilizado na área clínica.

\footnotetext{
${ }^{4}$ Weinrich, H. (1994), La memoire linguistique de 1'europe, in Langages, 114. "Comment expliquer cette indiffrence insouciante que governe les rapports, pour ne pas dire l'absence de rapports, entre la psycologia de la mémoire et les écoles dominantes de la linguistique, même au sein de la science cognitive?" (p.14)

${ }^{5}$ Bertolucci, P. (1999), Vídeo de divulgação do "Mini Exame do Estado Mental” (MEEM).
} 
Para averiguar a memória de fixação, solicita-se ao sujeito que repita uma série de palavras, por exemplo, "vaso, carro e tijolo". A chamada memória de evocação consiste em evocar, depois de um intervalo de tempo, a série de palavras anteriormente apresentada. Já a memória verbal é avaliada solicitando-se ao sujeito que repita uma outra série de palavras. Vejamos um exemplo de avaliação deste último tipo de memória. O exemplo refere-se a tarefas solicitadas pelo investigador (INV) a uma senhora de 74 anos que recebera o diagnóstico de demenciação em estágio inicial, identificada por SE (sujeito entrevistado).

(1) Memória Verbal

INV-Vamos voltar para a memória, Dona Nair. Eu vou mostrar pra senhora algumas palavras que a senhora vai ler em voz alta. Preste atenção, pois assim que acabar de ler, a senhora vai repetir as que conseguir lembrar.

SE-//O investigador lê para a senhora entrevistada uma série de palavras// Janela, gato, soldado, loja, tapete, bola, mesa, sapato.

INV-O que é que a senhora consegue lembrar disso aí?

SE-Janela, mesa, bola, tijolo.

INV-Alguma outra?

SE-Não.

INV-Agora eu vou mostrar de novo as mesmas palavras, só que estão em outra ordem. A senhora vai ler de novo e depois vai repetir as que a senhora conseguir lembrar.

SE-//O investigador lê novamente a série de palavras em uma outra ordem.// Soldado, tapete, sapato, janela, gato, bota, mesa.

INV-O que é que a senhora consegue lembrar?

SE-Bola, janela, mesa, tijolo.

INV-Alguma outra?

SE-Não.

A expectativa com esta tarefa é que o sujeito seja capaz de evocar pelo menos cinco palavras, principalmente na segunda tentativa, conforme se observa nas orientações destinadas aos aplicadores dos testes. Note-se que, ainda que se pretenda diferenciar a memória de evocação e verbal, esses conceitos se confundem e se resumem a conteúdos lingüísticos e mnêmicos armazenados no cérebro.

Para analisar a linguagem, supondo-se então uma distinção entre linguagem e memória passível de ser testada, há um conjunto de tarefas que engloba definição de objetos apresentados aos sujeitos, como por exemplo, caneta, relógio, repetição de expressões como "nem aqui, nem ali, nem lá", atendimento de comandos verbais e escritos, escrita de frases e a evocação de séries de palavras, em um intervalo de tempo, pertencentes a uma mesma categoria, como por exemplo, nomes de animais.

Observando essas tarefas, notamos uma redução da relação linguagem e memória a dois extremos: de um lado, uma forte dicotomia entre os dois processos, de outro lado, a idéia de que linguagem e memória, estando reportadas ao domínio mental, são entendidas como uma mesma coisa. Nos dois extremos, a relação entre linguagem e memória não poderia ser estabelecida em outras bases que não a instrumental, na qual uma é entendida como informação e a outra como processamento mental dessa informação. Partindo também de uma visão representacional dos dois processos, os dados obtidos nos testes revelam que a linguagem é ou condição ou obstáculo para a memória, como ilustram os dados 2 e 3 . 
(2)

INV-Dona N., agora eu vou mostrar para senhora algumas figuras. A senhora vai olhar e vai me dizer o que é cada figura.//O investigador mostra à dona N. a figura de uma árvore// SE-Árvore.

(3)

INV-//O investigador mostra à dona N. a figura de um apito//

SE-Isto aí parece uma bicicleta.

INV-Não. É um brinquedo, mas não é uma bicicleta. É um brinquedo que faz barulho.

SE-Mas a bicicleta não é um brinquedo?

INV-É um brinquedo que faz barulho, a gente assopra e faz barulho.

SE-Não sei.

Essas duas tarefas compõem o chamado "Teste de Nomeação", cujo objetivo é avaliar a linguagem do sujeito testado, que deve, por sua vez, nomear figuras que vão sendo apresentadas em seqüência. Tarefas deste tipo ilustram como a relação entre linguagem e memória está presente nas baterias de testes. Aqui, a atividade (referencial) da linguagem é concebida como uma correspondência unívoca (representacional) entre língua e conteúdos da memória, ou ainda entre língua e mundo. Nessa concepção, a linguagem é o meio de acesso [em 2], ou obstáculo para recuperação imediata [em 3] de conteúdos armazenados na memória.

A análise dos dados produzidos nessas tarefas não permite nenhum outro tipo de interpretação sobre o desempenho ou os processos utilizados pelos sujeitos que não seja a já prevista pelos testespadrão, pautada em termos de erro e acerto, em termos do que é normal e do que é patológico. Dona N., no exemplo 3, tenta construir o referente e arbitrar a referenciação em torno de bicicleta na própria interação. Teorizações lingüísticas de base sócio-interacionista, como os trabalhos de Mondada \& Dubois (1995), Koch (2001), Marcuschi (2001) ou Morato (2001), para citar alguns, certamente investiriam de sentido o percurso referencial feito por dona $\mathrm{N}$.

Todavia, os testes procuram fazer emergir dos sujeitos entrevistados aquilo que consideram ser sua capacidade mnêmica e, a partir da comparação com o desempenho de sujeitos normais (o tradicional grupo controle), identificar as "falhas" e aferir parâmetros de normalidade e patologia, ou de envelhecimento normal e senil. Assim, não seriam apenas as concepções subjacentes aos testes aquilo que é capaz de nos mostrar a relação entre linguagem e memória, mas, principalmente, o contexto de produção daquilo que será chamado de memória; grosso modo a forma como ela se exibe é o que a define. Estando a memória sempre creditada a um domínio mental, concluímos que o funcionamento da memória está alheio à ordem da linguagem.

\section{O ESTUDO DA MEMÓRIA SOB O ENFOQUE DE UMA NEUROLINGÜÍSTICA DE ABORDAGEM ENUNCIATIVO-DISCURSIVA}

Levando em conta as considerações acima sobre a redução da relação existente entre linguagem e memória e sob o enfoque de uma Neurolingüística instanciada discursivamente, é possível compreender os limites e os alcances dos modelos explicativos fornecidos pela pesquisa cognitiva a respeito da memória. Não nos é possível extrair nada a respeito da relação linguagem e memória se esta estiver baseada em termos de instrumentalidade, como sugerem os testes, nem tampouco se relacionarmos de forma constitutiva processos que são diferentes, como processos mnêmicos e processos lingüísticos, lembrando a discussão de Benveniste. 
No campo da Neurolingüística, o questionamento sobre essa relação acaba por encontrar em contextos patológicos indícios empíricos relevantes. Nos estudos tradicionais sobre as demências e as afasias, ou seja, sobre o que a literatura clássica sobre o tema considera déficits de memória e de linguagem respectivamente, é possível identificar uma forte dicotomia entre linguagem e cognição. É corrente a acepção de que as afasias diriam respeito primariamente a um deficit do tipo metalingüístico "clássico" (ou seja, relativo ao sistema lingüístico, stricto sensu), enquanto que as demências comprometeriam primariamente a cognição. Sendo basicamente a memória o processo cognitivo alterado nas demências (Lebrun,1989; Damásio, 1996; Défontaines, 2001), não nos escapa a observação de que há uma forte dicotomia entre linguagem e memória nos estudos neurolingüísticos clássicos.

Ao mesmo tempo em que os quadros afásicos e demenciais servem de parâmetros para a distinção entre linguagem e cognição, os problemas de linguagem são inadvertidamente chamados pelos neuropsicólogos ou neurocientistas de afasia ${ }^{6}$, na descrição semiológica da síndrome demencial. Ocupando um lugar dentre os processos cognitivos afetados pela neurodegenerescência, mais especificamente a Doença de Alzheimer (DA) ${ }^{7}$, "problema de linguagem" surge na semiologia das demências em geral após a identificação do "problema de memória”. O contexto patológico parece nesse caso um lugar de evidência de dissociações entre o lingüístico e o cognitivo. Através de tarefas como as apresentadas acima, nos exemplos 1, 2 e 3, pela consideração do método de aplicação dos testes (que, de forma reduzida, caracteriza-se por uma situação não usual para o exercício da linguagem e da memória) e pela consideração das bases conceituais que os fundamentam, não é possível arbitrar o que há entre os dois processos.

Em outro contexto de produção diferente dos testes (no qual as tarefas demandadas ocorrem fora de qualquer contexto significativo de produção e interpretação), realizei um estudo qualitativo com oito sujeitos, quatro com afasia e quatro com DA, mostrando que a forte distinção entre problemas de linguagem e de memória nos quadros afásicos e demenciais devem ser repensados. Realizei com os sujeitos entrevistas baseadas em relatos autobiográficos e comentários sobre as dificuldades de memória e de linguagem, bem como a exposição de sua concepções sobre essas duas noções. Esses fenômenos que procurei reunir em um Protocolo de Estudos são atos enunciativos, extraídos de situações interlocutivas que permitiram, através de atividades de remissão, marcadas pela heterogeneidade discursiva, tratar a relação em linguagem e memória em processo, ou seja, em um contexto que exigiu simultaneamente um trabalho de memória e de linguagem.

Com isto, a memória constituiu-se, assim como a linguagem, um processo cognitivo complexo, que não depende apenas de zonas corticais, mas também de outros fatores em jogo nas atividades simbólicas humanas, existindo, dessa forma, em função das atividades significativas da vida em sociedade, por um exercício de subjetividade e consciência, por práticas discursivas que regem os processos civilizatórios como a cultura, a arte, a ciência, como aponta Morato (1995).

A partir deste estudo, pude verificar um trabalho de reformulação discursiva ou de estratégia “cognitivo-langagière" (Fuchs, 1994) dos sujeitos que operam sobre a língua, no interior da linguagem

${ }^{6}$ A afasia é uma "perturbação da linguagem em que há alteração de mecanismos lingüísticos em todos os níveis, tanto do seu aspecto produtivo (relacionado com a produção de fala), quanto interpretativo (relacionado com a compreensão e com o reconhecimento de sentidos), causada por lesão estrutural adquirida no Sistema Nervoso Central, em virtude de acidentes vasculares cerebrais (AVCs), traumatismos crânio-encefálicos (TCE's) ou tumores". In Morato et al. (2002), As afasias e os afásicos: subsídios teóricos e práticos elaborados pelo Centro de Convivência de Afásicos , Campinas, SP: Editora da Unicamp.

${ }^{7} \mathrm{Na}$ literatura clássica, a Doença de Alzheimer, mais comumente chamada de Demência de Alzheimer, é definida como uma demência degenerativa progressiva, que afeta regiões cerebrais responsáveis por diversas atividades cognitivas, como por exemplo processos de memória, como a codificação e a evocação e o processamento da linguagem. (cf. Damásio, 1996; DMS-IV, 1995). 
e sobre a memória, posicionando-se reflexivamente em relação a esses dois processos, como mostram os exemplos 4 e 5 .

(4)

(16/09/2002) MN, uma senhora de 74 anos, comenta sobre suas dificuldades da afasia. MN havia acabado de contar a história de sua vinda para o Brasil, em 1955. Sua narrativa continha muitos detalhes e então a investigadora comenta sobre sua memória:

FC: A senhora tem uma memória!

MN: Mas a minha memória, minha memória é boa, o que não é bom, eu não sei o que hei de falar, eu sei o que quero contar uma coisa que eu estou a contar, mas não sei as palavras que hei de empregar.

FC: A senhora acha que aí é um problema com memória e com a linguagem?

$\mathrm{MN}$ : Acho que é uma coisa e outra. Acho que a memória fica me, eu fico pensando assim a palavra que eu hei de dizer, e se eu digo assim, eu digo uma qualquer e aí não combina. E se eu fico assim, fico, não sei se vem a palavra certa. Se eu fico/ deixa pra lá. Não vem a palavra certa. ... Eu não vejo a palavra. Eu sei o que deve ser falado, mas eu não sei falar, num sei... falar.

(5)

(16/12/2002) BG, uma senhora com 53 anos, com diagnóstico de DA, comenta sobre suas concepções de memória:

FC: BG, o que a senhora acha que é a memória?

BG: A memória é uma: ... quem tem a memória boa, é: bom, né? Mas eu já esqueço um pouco, né? Eu já esqueço um pouco, mas, mas ainda tá um pouquinho batendo aqui./lapontando para a cabeça.//

FC: Se a senhora fosse falar o que é a memória pra senhora, o que a senhora falaria?

BG: A memória minha, as frases que aparece eu falo, né? Mas não muito não, né?

FC: E o que que é o esquecimento para senhora?

BG: Ah, pra mim ... Num sei. //Ri.//

FC: A senhora acha que é importante esquecer algumas coisas?

BG: Ah, eu num gostava de /segmento ininteligível/, eu tenho, né? ...

A partir da consideração dos processos lingüísticos e mnêmicos envolvidos nessas duas entidades nosológicas, um conjunto de problemas teóricos e metodológicos se abrem. As avaliações de linguagem e de memória nas demências são feitas com base nos mesmos testes utilizados para se averiguar as alterações de linguagem nas afasias. Com isto, somos levados a supor que as alterações de linguagem se apresentam da mesma forma nas duas patologias, ou ainda pelo menos que elas se dão a conhecer pelos mesmos procedimentos clínico-metodológicos. Deriva-se dessa suposição a assunção de que as alterações em um processo não alterariam a constituição do outro.

Se tradicionalmente a afasia é entendida como um problema de linguagem e as demências como um problema de memória, parece claro que os dois processos não se confundem, nem para os especialistas que analisam os dados de afasia e de demência, nem para os autores de testes que elaboram tarefas destinadas a avaliar separadamente a memória e a linguagem, conforme vimos nos exemplos 1, 2 e 3 . No entanto, conforme os dois últimos fragmentos mostrados acima, ao contrapor os dados obtidos em testes, pautados nas explicações científicas sobre as alterações desses dois processos à fala dos sujeitos, pautada em sua experiência sensível com essas alterações, colocamos 
em questão a forte distinção entre linguagem e memória. Basicamente, coloca-se em cena o confronto entre um metadiscurso clínico sobre a memória e um discurso de memória.

\section{ALGUMAS CONSIDERAÇÕES FINAIS}

Além das considerações feitas acima a respeito da forte dicotomia entre linguagem e memória nos dois contextos patológicos em questão, a análise das entrevistas revelou papéis diferentes da linguagem frente à memória: ao invés de mero instrumento, como nos testes, a linguagem acaba por ocupar uma função reflexiva frente à própria linguagem e frente à memória. Outro ponto a considerar é o quanto é produtivo, teórico-metodologicamente, pensar nos processos enunciativos envolvidos na construção dos sentidos sobre a memória e a linguagem no campo das práticas com a linguagem (suas regularidades e indeterminações). Nesse campo, muitas evidências empíricas reforçam a hipótese de que a relação entre memória e linguagem revela-se, especialmente, nos atos de linguagem, portanto, na ação entre interlocutores.

Nossas práticas com a linguagem são um pouco de acumulação (constitutiva) do sentido e nossas memórias, por sua vez, são uma espécie de acumulação de nossas práticas de linguagem. Isso nos conduz à observação de que a compreensão da memória exige a consideração de ações de seletividade, de interpretação, de sentidos e de distorção, atividades que estão intimamente ligadas aos processos de significação constituídos pela linguagem, capazes de indicar a vitalidade e a manutenção da memória, bem como sua falibilidade.

Uma abordagem enunciativo-discursiva da memória em contextos de alterações de memória e de linguagem contribui heuristicamente para o entendimento da cognição humana, especialmente no âmbito das patologias lingüístico-cognitivas. Se o conceito de memória parte de sua relação com os fenômenos humanos e sociais, e se os processos sensório-perceptivos e biológicos sozinhos não dão conta de explicá-la, é preciso relacionar linguagem e memória com base nos processos que mutuamente a constituem, como os processos discursivos, psicológicos, sócio-culturais e subjetivos.

\section{$\overline{\text { REFERÊNCIAS BIBLIOGRÁFICAS }}$}

BENVENISTE, E. (1988) Problemas de Lingüística Geral. Campinas, SP: Pontes.

BOSI, E. (1994) Memória e Sociedade - Lembrança de Velhos. São Paulo: Cia das Letras.

CHARAUDEAU, P. \& Maingueneau, D. (2002) Dictionaire d'analyse du discours. Paris: Ed. Seuil.

CHOMSKY, N. (1968) Language and mind. New York: Harcourt, Brace and World.

CHRISTENSEN, A. (1987) El diagnóstico neurológico de Luria. Buenos Aires: Visor.

COURTINE, J-J. (1994) Le tissu de la mémoire: quelques perpectives de travail historique dans les sciences du langage. In Langages, 114, pp.5-12. (1981) Analyse du discours politique. in Langages, 62.

FOLSTEIN, M. Folstein, S. \& McHugh, P. (1974) Mini Mental State in Journal Psychiat, Vol.12, pp. 189/198.

FREUD, S. (1987) Sobre a Psicopatologia da Vida Cotidiana. Rio de Janeiro: Imago.

FUCHS, C. (1994) Paraphrase et Enontiation, Paris: Ophrys. 
HALBWACHS. M (1990) A Memória Coletiva. São Paulo: Edições Vértice.

KOCH, I.G.V. (2001) A referenciação como atividade cognitivo-discursiva e interacional. Cadernos de Estudos Lingüísticos, $\mathrm{n}^{\circ} 41$, pp. 75-90, Campinas: SP.

LEBRUN, Y.(1988) Alzheimer versus Broca e Wernicke. Aphasiology. 2, pp.

MAINGUENEAU, D. (1989) Novas Tendências em Análise do discurso. Campinas, São Paulo: Ed. Pontes.

MARCUSCHI, L. A. (2001) Atos de referenciação na interação face à face. Cadernos de Estudos Lingüísticos. $\mathrm{n}^{\circ} 41$, pp. 37-54, Campinas: SP.

MORATO, E.M. (1995) Um estudo da confabulação no contexto neuropsicológico: o discurso à deriva ou as sem-razões do sentido. Tese de Doutoramento. Campinas-SP.

(2001) (In)determinação e subjetividade na linguagem de afásicos: a inclinação anti-referencialista dos processos enunciativos. Cadernos de Estudos Lingüísticos. n ${ }^{\circ}$ 41, pp. 55-74, Campinas: SP.

et. al. (2002) As afasias e os afásicos: subsídios teóricos e práticos elaborados pelo Centro de Convivência de Afásicos (CCA). Campinas: Editora da Unicamp.

ROSENFIELD, I. (1994) A invenção da memória: uma nova visão do cérebro. Rio de Janeiro: Nova Fronteira

SAUSSURE, F. (1977) Curso de Lingüística Geral, São Paulo: Cultrix.

VAN DIJK (1988). Cognição, Discurso e Interação. São Paulo: Contexto.

WEINRICH, H. (1994) La mémoire linguistique de l'europe. In Langages. 114, pp. 13-22. 